Fifth International Conference on Sustainable Construction Materials and

Technologies. http://www.claisse.info/Proceedings.htm

\title{
SUSTAINABLE USE OF SUPPLEMENTARY CEMENTITIOUS MATERIALS FROM AGRICULTURAL WASTES - A REVIEW
}

Oluwadamilola, Fadele and Mike, Otieno

School of Civil and Environmental Engineering, University of the Witwatersrand, Private mail bag 3, Braamfontein 2000, Johannesburg, South Africa

\begin{abstract}
This paper presents a critical literature review on the use of supplementary cementitious materials (SCMs) from agricultural wastes (mainly from crop residues) in cementitious systems. The current utilisation of these materials as partial replacement of Portland cement (PC) is reviewed with respect to the materials' characteristic influence on performance and limit of replacement in cementitious systems. In-spite of the benefits of SCMs from agricultural wastes (such as rice husk ash, palm oil fuel ash, sugarcane bagasse ash), their heterogeneous nature coupled with insufficient data make it difficult to generalise their performance.

Therefore, unravelling the relationship between the influence of the processing method and materials characteristics on the limit of replacement and performance in cementitious systems is essential to their standardisation and sustainable utilisation. This, coupled with the reproducibility of results will assist the processing and adoption of other agricultural wastes in cementitious systems.
\end{abstract}

Keywords: Supplementary cementitious materials; agricultural wastes, portland cement, Sustainable utilisation

\subsection{INTRODUCTION}

Sustainability is generally defined as meeting present needs without compromising the ability of future generations to meeting their needs; which implies judicious use of resources (UN, 1987). The environment has a major pool of resources which are exploited by man for development and may serve as reservoir of hazards that can endanger its ecosystem if not efficiently managed. To date construction materials rely heavily on nonrenewable virgin environmental resources either in raw or processed form. For instance, steel, cement, lime and glass are produced from non-renewable natural resources while crusher mineral rocks used as aggregates are also sourced from naturally occurring materials. 
The sustainability of Construction materials requires efficient use of these non-renewable materials in such a way that they will not infringe the access of future generations to these resources for development nor binder their access to a healthy environment. This 
should be a necessary consideration in developing countries given the growing need for both housing and infrastructural development amidst fast growing population and dwindling economy (United Nations, 2018). Therefore, it is crucial to ensure ecological balance by reducing the environmental burden of activities related to the production and utilisation of construction materials in line with global best practices. This necessitates the paradigm shift in the production and utilisation of Portland cement (PC) globally as it incorporates supplementary cementitious materials (SCMs) in a bid to lower its negative impact on the environment today. Partial substitution of PC with SCMs offers the advantages of reduced energy consumption and reduced greenhouse gas emissions associated with PC production (Mikulčić et al., 2016) as well as the possibility of having a construction material with improved properties (i.e. strength and durability). Other benefits of SCMs include reduced waste streams and disposal burden by recycling waste for alternative (economic) use, improving materials' quality to expand life cycle of structures, use of renewable wastes in lieu of non-renewable resources thereby reducing burden on non-renewable resources.

Currently, SCMs from industrial waste streams (e.g. silica fume, SF, pulverised fuel ash, PFA, granulated ground furnace slag, GGBS) and some naturally occurring ones (e.g. volcanic ash) are available in commercial quantities and have been standardised in developed countries. On the other hand, SCMs especially those from agricultural wastes, are yet to be fully utilised in developing countries despite the abundance of the raw materials and the potential material properties that may be harnessed to improve concrete performance. This necessitates this review, which examines in brief, the scope and limitations of existing studies on these underutilised SCMs with a view to enhancing their utilisation and development of standards to guide their use, especially in developing countries. This will encourage the use of locally available supplementary materials which may require improving available technology to suit their production towards increase utilisation. Subsequently, this necessitates an appraisal of current technologies to enhance effective decision-making on the development and production of these materials.

\subsection{Supplementary Cementitious Materials}

SCMs are materials possessing latent hydraulic or pozzolanic properties, and as a result can partially substitute PC as binder in cementitious systems. They include natural materials, industrial by-products and/or agricultural (and agro-allied) wastes. They are distinct from fillers which influence mechanical and/or microstructural properties of concrete only by their physical presence. SCMs from industrial activities and some natural ones (e.g. PFA, GGBS, SF and metakaolin) have been deeply researched and standardised, which are widely available in commercial quantities in developed countries (Gutteridge and Dalziel, 1990; Suprenant and Papadopoulos, 1991; Singh et al., 2000; Otieno et al., 2010; Monteagudo et al., 2014). These materials essentially contain calcium, silica, alumina, iron oxide and some alkalis in varying proportions which make them suitable as partial substitutes for PC. 


\subsection{SCMs from Agricultural Wastes}

Agricultural based SCMs are pozzolanic materials processed from crop residues emanating from the harvest and/or post-harvest processing of plant and tree crops. Examples are rice husk ash, wheat straw ash, corn cob and husk ash, palm oil fuel ash, palm kernel fibre and shell ash, sugarcane straw and bagasse ash, groundnut shell ash, coconut husk and shell ash. A large quantity of these crop residues is often burnt in open air or piled up in open field to decompose biologically, thereby constituting environmental nuisance. Therefore, better and sustainable ways of handling are essential, one of which is reusing these wastes in construction activities by recycling them as alternative binding materials (SCMs).

Processing agricultural waste into SCMs will require a lower energy input than is required for PC production; but notably for most developing countries, such energy requirement may not be readily available (Choate, 2003). However, these materials may be explored as an alternative fuel source to generate the energy needed to convert them into SCMs either solely or combined with conventional fuel sources like coal (Asonja et al., 2017). This offers the advantage of reducing emissions while enhancing a cleaner environment. Also, since these wastes are renewable, their use will bring about a reduced pressure on exploitation of non-renewable natural fuel sources like coal while ensuring environmental sustainability. Furthermore, the combustion of these wastes for energy production as noted by Commission for environmental cooperation report (2014) presents a cheaper option when compared with converting them to biofuels (ethanol and biodiesel).

Investigations on the use of some SCMs from agricultural origin: rice husk ash, palm oil fuel ash and sugarcane bagasse ash (to some extent) (Megat Johari et al., 2012; Rukzon and Chindaprasirt, 2012; Cordeiro, Tavares and Filho, 2016; Wi et al., 2018) have been widely reported while some others (corn husk/cob ash, wheat straw ash etc.) require more intensive investigations to understand their behaviour and enhance their utilisation. However, irrespective of the level of investigation on these SCMs, commercial utilisation is not yet substantial. A likely reason for their low utilisation may be the non-availability of some of these SCMs in ready-to-use forms coupled with the need for further thermal treatment in some cases which brings about variations in their behaviour and performance from laboratory investigations. Therefore, there is the need for more concerted efforts in research toward the development of these materials and standards to guide their use; given the immerse benefits that can accrue from their utilisation.

\subsection{Influence of Processing Methods on Properties of SCMs from Crop Residues}

The physical, chemical and mineralogical properties of agricultural based SCMs are strongly dependent on the extent of the thermal and mechanical treatment of the initial crop residue and resulting ashes. The method of combustion employed (open air burning, combustion in boilers and calcination in laboratory furnaces) as well as the calcination temperature and duration introduce significant variability in the properties of the ash (carbon content, shape and sizes of the particles) (Nimityongskul and Daladar, 1995; Ismail and Waliuddin, 1996; Nehdi, Duquette and El Damatty, 2003; Cordeiro et al., 
2008; Adesanya and Raheem, 2009; Salas et al., 2009a; Muthadhi and Kothandaraman, 2010; Bahurudeen and Santhanam, 2015; Fadele and Ata, 2016; Fernandes et al., 2016; Sanawung et al., 2017). The as-obtained ash properties will determine the extent of further treatment that may be required to enhance performance in cementitious systems. Furthermore, chemical pre-treatment of the initial crop residue prior to calcination has been reported to enhance some chemical constituents and mineralogical properties of the ash (Feng et al., 2004). However, the cost of such pre-treatment may need to be assessed against the reported improvement in materials' properties and performance in cementitious systems.

Generally, agricultural pozzolans (e.g. Palm oil fuel ash (POFA), sugarcane bagasse ash (SCBA) and rice husk ash (RHA)) are reported to be highly porous with low specific gravity and they have large particles with rough edges and surfaces (Sata, Jaturapitakkul and Kiattikomol, 2004; Rukzon, Chindaprasirt and Mahachai, 2009; Aigbodion et al., 2010). However, the initial coarseness and/or carbon content of the ash will determine the extent of further thermal treatment and/or grinding that may be required to enhance the fineness of the particles. This may be necessary to enhance their reactivity and performance in cementitious systems (Megat Johari et al., 2012). Also, the carbon content in the ash can impact some of these properties and the water demand in fresh cementitious systems (Rukzon, Chindaprasirt and Mahachai, 2009; Chandara et al., 2010; Bahurudeen and Santhanam, 2015).

\subsection{Significance of Chemical and Mineralogical Characteristics}

The classification of ashes obtained from the combustion of agricultural waste materials as SCMs often lies in their chemical characteristics especially the silica, alumina and/or iron oxide content as well as the reactivity of the silica as stated in ASTM C618-12a and BS EN 197-1:2000. The reactivity of the ash is dependent on its mineralogical properties which influences to a large extent, the cementitious properties and subsequent performance in cementitious systems. Likewise, the presence of some minor oxides like $\mathrm{K}_{2} \mathrm{O}, \mathrm{Na}_{2} \mathrm{O}, \mathrm{P}_{2} \mathrm{O}_{5}$ contributes to ash transformation during combustion while their influence on the mineralogical properties may depend on the burning conditions (Boström et al., 2012). Furthermore, acid pre-treatment of crop residue has been noted to reduce these minor oxides which invariably reduce their effect on the chemical and mineralogical characteristics of the ash (Feng et al., 2004). A good understanding of the variability of properties with treatment type and extent given good repeatability and reproducibility of laboratory results is considered essential. This will assist in developing these SCMs for commercial utilisation, improving their performance (where necessary) and developing standards or guidelines to regulate their use. Also, the differences in their mineralogical composition with respect to chemical composition, to great extent, influences their pozzolanic properties but its relation to the quantity that can be effectively utilised without adverse effect in cementitious systems is yet to be fully understood. 


\subsection{Mechanical Behaviour of SCMs in Concrete}

SCMs from agricultural wastes have been reported to be suitable for the production of normal, high and ultra-high strength concrete either in binary combination with PC or combined with other industrial SCMs (FA, SF) and PC (Zhang and Malhotra, 1996; Salas et al., 2009; Chatveera and Lertwattanaruk, 2011; Van Tuan et al., 2011; Megat Johari et al., 2012; Hussein et al., 2014; Van et al., 2014; Zareei et al., 2017; Arel and Aydin, 2018). Compressive strength values ranging from about $20 \mathrm{MPa}$ to above $95 \mathrm{MPa}$ have been reported at 28 days for RHA, POFA and/or SCBA with the values either lower, comparable to or higher than that of plain PC concrete (Ismail and Waliuddin, 1996; Chindaprasirt, Rukzon and Sirivivatnanon, 2008; Ramezanianpour, Mahdi and Ahmadibeni, 2009; Chao-Lung, Anh-Tuan and Chun-Tsun, 2011; Rukzon and Chindaprasirt, 2012; Megat Johari et al., 2012; Van et al., 2014; Bahurudeen et al., 2015). Also, these SCMs have better strength at early ages compared to fly ash. For instance, significant strength gain was achieved at 28days compared to strength gained beyond this age, while the rate of gain of strength was more rapid between 3 and 7 days. Furthermore, the 7-day strength was either comparable to or slightly higher than that of plain PC concrete which often times is not the case with fly ash (Van Tuan et al., 2011; Megat Johari et al., 2012; Vishwakarma et al., 2016; Zeyad et al., 2016).

However, it has been noted that RHA (in-spite of higher silica content) is rarely investigated beyond 30\% replacement level while PC replacement by POFA up to $60 \%$ without adverse effect on strength has been reported by Megat Johari et al., (2012). Also, SCBA which has similar silica content as POFA has been reported to have adverse effect on strength development when used up to and beyond 30\% (Shafiq et al., 2016). The factor(s) influencing the effective replacement level for each SCM in spite of having requisite chemical composition is not yet clear. This is further complicated by insufficient information on the mineralogical composition and variations in particles fineness, thermal treatment conditions and mix design (cement and water contents, aggregates size and proportion) as observed in most of the reports reviewed as shown in, Figures 1 and 2 below.

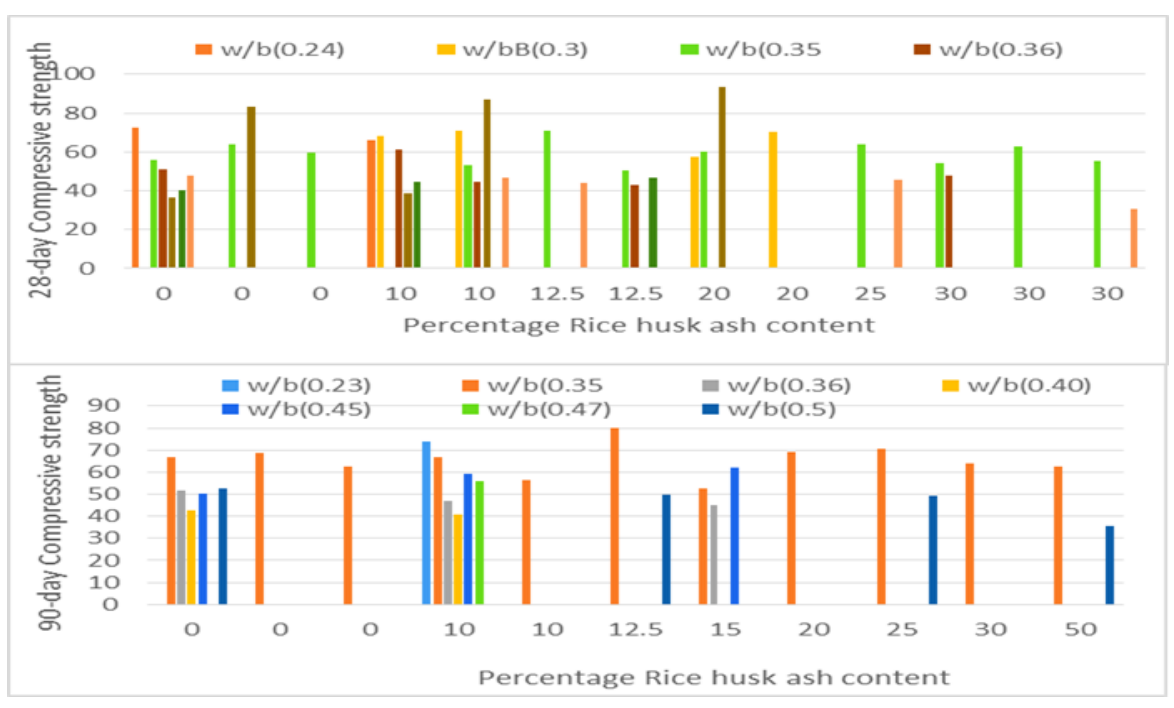


Figure 1: Average compressive strength of rice husk ash-cement concrete (extracted from the cited references)

Also, for other strength parameters, agricultural based SCMs showed similar behaviour to that of compressive strength. For instance, tensile and flexural strength as well as the modulus of elasticity either comparable to, lower or higher than that of plain PC concrete have been reported for different proportions of these SCMs in concrete, with significant effects noticed at 28 days and beyond (Kishore, Bhikshma and Jeevana Prakash, 2011)(Tangchirapat and Jaturapitakkul, 2010)(Sata, Jaturapitakkul and Kiattikomol, 2004). It is also worth noting that the strength contribution of these SCMs becomes significant at 28 days than at earlier ages, hence their utilisation in concrete may not affect early age strength requirement depending on the strength requirement at ages earlier than 28 days.

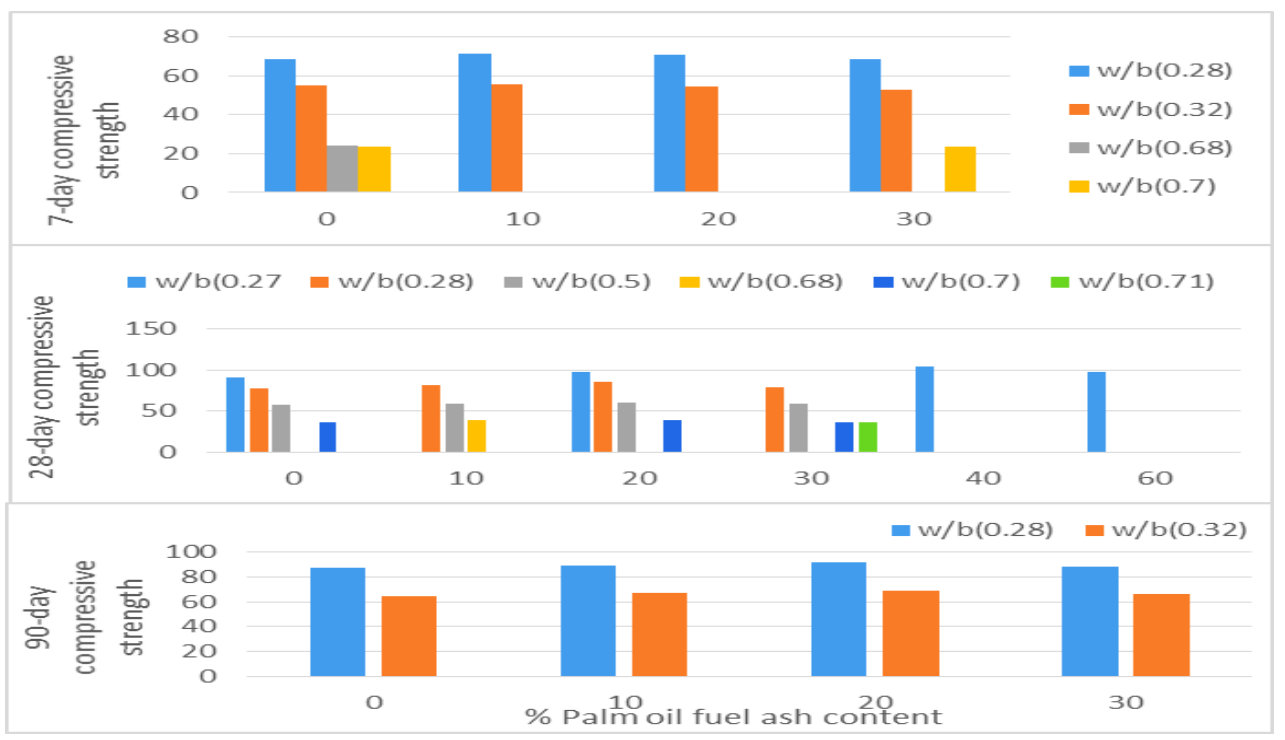

Figure 2: Average compressive strength of palm oil fuel ash-cement concrete (extracted from the cited references)

\subsection{Durability Behaviour of SCMs in Concrete}

The durability performance of pozzolans from agricultural wastes with respect to the ingress of fluids and process that may induce cracks (shrinkage) has been reported. With regard to fluid ingress, reduced penetrability of concrete containing these SCMs has been reported and often times linked to refinement of the pores structure. The extent of improvement or otherwise varies with particles' fineness, reactivity and carbon content of the ash as well as the w/b ratio of the mix and aggressiveness of the exposure environment as observed in the studies of (Hussin et al., 2009; Ramezanianpour, Mahdi and Ahmadibeni, 2009; Adesanya and Raheem, 2010; Chatveera and Lertwattanaruk, 2011). In addition, the inclusion of POFA, RHA and SCBA was reported to reduce the porosity, surface absorption and penetrability of concrete by fluids (gas, chloride ions, water) compared to PC while the porosity reduces with increasing POFA content 
(Rukzon, Chindaprasirt and Mahachai, 2009; Salas et al., 2009; Megat Johari et al., 2012; Bahurudeen et al., 2015).

Also, POFA having finer particles than PC was shown to reduce drying shrinkage and water permeability than that with coarser particles than PC (Tangchirapat and Jaturapitakkul, 2010). Salas et al. (2009) further showed that chemical pre-treatment of crop residue prior to calcination improved resistance to fluids penetration. This may be as a result of the reduced alkali content and its influence on both the chemical and mineralogical composition of the ash as reported by (Feng et al., 2004). However, given limited information in this regard, further investigation is required to substantiate this proof and also to test the effect beyond 10\% SCM content. Also, expansion or loss of strength due to sulphate or acid attack was reported to be lower in specimens containing SCMs than in plain PC depending on the SCM content in test samples (Chatveera and Lertwattanaruk, 2009)(Chatveera and Lertwattanaruk, 2011).

In addition, fine agricultural based SCMs (RHA, POFA and SCBA) showed lower but marginal effect on drying shrinkage when compared to plain PC samples (Zhang and Malhotra, 1996)(Bahurudeen et al., 2015)(Tangchirapat and Jaturapitakkul, 2010). However, with increase in carbon content and w/b ratio, higher shrinkage than that in PC samples was reported for samples containing RHA which reduces with increasing RHA content (Chatveera and Lertwattanaruk, 2011). Tentatively, agricultural-based pozzolans reduce the penetrability of cementitious systems and as such, may enhance durability. However, the influence of these SCMs on major concrete deterioration mechanisms aside chemical attack is yet to be fully explored. This may be necessary to understand their

application in heavy construction projects given that they often reduce the heat of hydration of PC while some may contain significant amount of alkali oxides.

\section{CONCLUSION}

The inclusion of agricultural based SCMs no doubt contributes to both the strength and durability performances of cementitious systems, with considerable numbers of research on RHA, POFA and to a lesser extent SCBA, yet underutilised. Clearly, fineness of particles subject to their reactivity and coupled with cement content influences to a larger extent the performance of agricultural SCMs. Notably, the optimum replacement level of PC by some agricultural SCMs is still limited while the impact of the type and extent of thermal and/or mechanical treatment on their properties and performance in cementitious systems is not yet clearly understood. Subsequently, the variations in behaviour and insufficient information in the reports reviewed indicate the need for more investigations. This will improve the understanding of the influence of their properties on behaviour in cementitious system which may further enhance repeatability and reproducibility of laboratory results towards utilization and development of standards to guide their use.

\section{ACKNOWLEDGEMENT}

The authors wish to acknowledge with gratitude the financial support received from The Concrete Institute, The South African National Research Foundation and The world 
academy of Science.

\section{REFERENCES}

Adesanya, D. A. and Raheem, A. A. (2009) 'Development of corn cob ash blended cement', Construction and Building Materials, 23(1), pp. 347-352.

Adesanya, D. A. and Raheem, A. A. (2010) 'A study of the permeability and acid attack of corn cob ash blended cements', Construction and Building Materials, 24(3), pp. 403409.

Aigbodion, V. S. et al. (2010) 'Potential utilization of solid waste ( Bagasse Ash )', Journal of Mineral and Materials Characterization \& Engineering, 9(1), pp. 67-77.

Arel, H. Ş. and Aydin, E. (2018) 'Use of industrial and agricultural wastes in construction concrete', ACI Materials Journal, 115(1), pp. 55-64.

Asonja, A., Desnica, E. and Radovanović, L. Z. (2017) 'Energy efficiency analysis of corn cob used as a fuel', Energy Sources, Part B: Economics, Planning and Policy, 12(1), pp. 1-7.

Bahurudeen, A. et al. (2014) 'Development of sugarcane bagasse ash based Portland pozzolana cement and evaluation of compatibility with superplasticizers', Construction and Building Materials, 68, pp. 465-475.

Bahurudeen, A. et al. (2015) 'Performance evaluation of sugarcane bagasse ash blended cement in concrete', Cement and Concrete Composites, 59, pp. 77-88.

Bahurudeen, A. and Santhanam, M. (2015) 'Influence of different processing methods on the pozzolanic performance of sugarcane bagasse ash', Cement and Concrete Composites, 56, pp. 32-45.

Boström, D. et al. (2012) 'Ash transformation chemistry during combustion of biomass', in Energy and Fuels, pp. 85-93.

Bullard, J. W. et al. (2015) 'Mechanisms of cement hydration', Science and Technology of Concrete Admixtures, 41(12), pp. 129-145.

Chandara, C. et al. (2010) 'The effect of unburned carbon in palm oil fuel ash on fluidity of cement pastes containing superplasticizer', Construction and Building Materials, 24(9), pp. 1590-1593.

Chao-Lung, H., Anh-Tuan, B. Le and Chun-Tsun, C. (2011) 'Effect of rice husk ash on the strength and durability characteristics of concrete', Construction and Building Materials, 25(9), pp. 3768-3772.

Chatveera, B. and Lertwattanaruk, P. (2009) 'Evaluation of sulfate resistance of cement mortars containing black rice husk ash', Journal of Environmental Management, 90(3), pp. 1435-1441.

Chatveera, B. and Lertwattanaruk, P. (2011) 'Durability of conventional concretes containing black rice husk ash', Journal of Environmental Management, 92(1), pp. 59- 
66.

Chindaprasirt, P., Rukzon, S. and Sirivivatnanon, V. (2008) 'Resistance to chloride penetration of blended Portland cement mortar containing palm oil fuel ash, rice husk ash and fly ash', Construction and Building Materials, 22(5), pp. 932-938.

Choate, W. T. (2003) Energy and Emission Reduction Opportunities for the Cement Industry, U.S. Department of Energy, Energy Efficiency and Renewable Energy.

Chusilp, N., Jaturapitakkul, C. and Kiattikomol, K. (2009) 'Utilization of bagasse ash as a pozzolanic material in concrete', Construction and Building Materials, 23, pp. 33523358.

Cordeiro, G. C. et al. (2008) 'Pozzolanic activity and filler effect of sugar cane bagasse ash in Portland cement and lime mortars', Cement and Concrete Composites, 30(5), pp. 410-418.

Cordeiro, G. C., Tavares, L. M. and Filho, R. D. T. (2016) 'Improved pozzolanic activity of sugar cane bagasse ash by selective grinding and classification', Cement and Concrete Research, 89, pp. 269-275.

Cordeiro, G. C., Toledo Filho, R. D. and Fairbairn, E. M. R. (2009) 'Effect of calcination temperature on the pozzolanic activity of sugar cane bagasse ash', Construction and Building Materials, 23(10), pp. 3301-3303.

Deschner, F. et al. (2013) 'Quantification of fly ash in hydrated, blended Portland cement pastes by backscattered electron imaging', Journal of Microscopy, 251(2), pp. 188-204.

Escalante, J. I. et al. (2001) 'Reactivity of blast-furnace slag in Portland cement blends hydrated under different conditions', Cement and Concrete Research, 31(10), pp. 14031409.

Fadele, O. A. and Ata, O. (2016) 'Compressive Strength of Concrete Containing Palm Kernel Shell Ash', American Journal of Engineering Research, 5(12), pp. 32-36.

Feng, Q. et al. (2004) 'Study on the pozzolanic properties of rice husk ash by hydrochloric acid pretreatment', Cement and Concrete Research, 34(3), pp. 521-526.

Fernandes, I. J. et al. (2016) 'Characterization of rice husk ash produced using different biomass combustion techniques for energy’, Fuel, 165, pp. 351-359.

Gutteridge, W. A. and Dalziel, J. . (1990) 'Filler cement: The effect of the secondary component on the hydration of Portland cement. Part 1: Fine Non-hydraulic fillers', Cement and Concrete Research, 20, pp. 778-782.

Haha, M. Ben, De Weerdt, K. and Lothenbach, B. (2010) 'Quantification of the degree of reaction of fly ash', Cement and Concrete Research, 40(11), pp. 1620-1629.

Hussein, A. A. E. et al. (2014) 'Compressive strength and microstructure of sugar cane bagasse ash concrete', Research Journal of Applied Sciences, Engineering and Technology, 7(12), pp. 2569-2577. 
Hussin, M. W. et al. (2009) 'Durability of High Strength Concrete Containing Palm Oil Fuel Ash of Different Fineness', Malaysian Journal of Civil Engineering, 21(2), pp. 180-194.

Isaia, G. C., Gastaldini, A. L. G. and Moraes, R. (2003) 'Physical and pozzolanic action of mineral additions on the mechanical strength of high-performance concrete', Cement and Concrete Composites, 25(1), pp. 69-76.

Ismail, M. S. and Waliuddin, A. M. (1996) 'Effect of rice husk ash on high strength concrete', Construction and Building Materials, 10(I), pp. 521-526.

Kishore, R., Bhikshma, V. and Jeevana Prakash, A. P. (2011) 'Study on Strength Characteristics of High Strength Rice Husk Ash Concrete', Procedia Engineering, 14, pp. 2666-2672.

Kroehong, W. et al. (2011) 'Effect of palm oil fuel ash fineness on the microstructure of blended cement paste', Construction and Building Materials, 25, pp. 4095-4104.

Lumley, J. S. et al. (1996) 'Degrees of reaction of the slag in some blends with Portland cements', Cement and Concrete Research, 26(1), pp. 139-151.

Luxán, M. P. et al. (1989) 'Rapid evaluation of pozzolanic activity of natural products by conductivity measurement', Cement and Concrete Research, 19(1), pp. 63-68.

Megat Johari, M. A. et al. (2012) 'Engineering and transport properties of high-strength green concrete containing high volume of ultrafine palm oil fuel ash', Construction and Building Materials, 30, pp. 281-288.

Mikulčić, H. et al. (2016) 'Reducing greenhouse gasses emissions by fostering the deployment of alternative raw materials and energy sources in the cleaner cement manufacturing process', Journal of Cleaner Production, 136, pp. 119-132.

Monteagudo, S. M. et al. (2014) 'The degree of hydration assessment of blended cement pastes by differential thermal and thermogravimetric analysis. Morphological evolution of the solid phases', Thermochimica Acta, 592, pp. 37-51.

Muthadhi, A. and Kothandaraman, S. (2010) 'Optimum production conditions for reactive rice husk ash', Materials and Structures/Materiaux et Constructions, 43(9), pp. 1303-1315.

Nehdi, M., Duquette, J. and El Damatty, A. (2003) 'Performance of rice husk ash produced using a new technology as a mineral admixture in concrete', Cement and Concrete Research, 33(8), pp. 1203-1210.

Nimityongskul, P. and Daladar, T. U. (1995) 'Use of coconut husk ash, corn cob ash and peanut shell ash as cement replacement', Journal of Ferrocement, 25(1), pp. 35-44.

Otieno, M. B., Alexander, M. G. and Beushausen, H.-D. (2010) 'Corrosion in cracked and uncracked concrete - influence of crack width, concrete quality and crack reopening', Magazine of Concrete Research, 62(6), pp. 393-404.

Rahman, M. E. et al. (2014) 'Self compacting concrete from uncontrolled burning of 
rice husk and blended fine aggregate', Materials and Design, 55, pp. 410-415.

Ramezanianpour, A. A., Mahdi, M. and Ahmadibeni, G. (2009) 'The Effect of Rice Husk Ash on Mechanical Properties and Durability of Sustainable Concretes', International Journal of Civil Engineerng, 7(2), pp. 83-91.

Rukzon, S. and Chindaprasirt, P. (2012) 'Utilization of bagasse ash in high-strength concrete', Journal of Materials and Design, 34, pp. 45-50.

Rukzon, S., Chindaprasirt, P. and Mahachai, R. (2009) 'Effect of grinding on chemical and physical properties of rice husk ash', International Journal of Minerals, Metallurgy and Materials, 16(2), pp. 242-247.

Salas, A. et al. (2009) 'Comparison of two processes for treating rice husk ash for use in high performance concrete', Cement and Concrete Research, 39(9), pp. 773-778.

Sanawung, W. et al. (2017) 'Influence of palm oil fuel ash and W/B ratios on aompressive strength, water permeability , and chloride resistance of concrete', Advances in Materials Science and Engineering, 2017, pp. 1-8.

Sata, V., Jaturapitakkul, C. and Kiattikomol, K. (2004) 'Utilization of Palm Oil Fuel Ash in High-Strength Concrete', Journal of Materials in Civil Engineering, 16(6), pp. 623-628.

Shafiq, N. et al. (2016) 'Effects of sugarcane bagasse ash on the properties of concrete', Engineering Sustainability, pp. 1-10.

Singh, N. B., Singh, V. D. and Rai, S. (2000) 'Hydration of bagasse ash-blended portland cement', Cement and Concrete Research, 30, pp. 1485-1488.

Suprenant, B. B. A. and Papadopoulos, G. (1991) 'Selective dissolution of portland-flyash cements', Journal of Materials in Civil Engineering, 3(1), pp. 48-59.

Tangchirapat, W. and Jaturapitakkul, C. (2010) 'Strength, drying shrinkage, and water permeability of concrete incorporating ground palm oil fuel ash', Cement and Concrete Research, 32, pp. 767-774.

Tangchirapat, W., Khamklai, S. and Jaturapitakkul, C. (2012) 'Use of ground palm oil fuel ash to improve strength, sulfate resistance, and water permeability of concrete containing high amount of recycled concrete aggregates', Materials and Design, 41, pp. $150-157$.

Van Tuan, N. et al. (2011) 'The study of using rice husk ash to produce ultra high performance concrete', Construction and Building Materials, 25(4), pp. 2030-2035.

UN (1987) United Nations: Our Common Future.

United Nations (2018) World Economic situation and prospects. New York.

Van, V.-T.-A. et al. (2014) 'Rice husk ash as both pozzolanic admixture and internal curing agent in ultra-high performance concrete', Cement \& Concrete Composites, 53, pp. 270-278. 
Vishwakarma, V. et al. (2016) 'Studies of rice husk ash nanoparticles on the mechanical and microstructural properties of the concrete', Materials Today: Proceedings, 3(6), pp. 1999-2007.

Wang, L., Hustad, J. E. and Grønli, M. (2012) 'Sintering characteristics and mineral transformation behaviors of corn cob ashes', Energy and Fuels, 26(9), pp. 5905-5916.

Wi, K. et al. (2018) 'Use of an agricultural by-product, nano sized Palm Oil Fuel Ash as a supplementary cementitious material', Construction and Building Materials, 183, pp. 139-149.

Zareei, S. A. et al. (2017) 'Rice husk ash as a partial replacement of cement in high strength concrete containing micro silica: Evaluating durability and mechanical properties', Case Studies in Construction Materials, 7, pp. 73-81.

Zeyad, A. M. et al. (2016) 'Efficiency of treated and untreated palm oil fuel ash as a supplementary binder on engineering and fluid transport properties of high-strength concrete', Construction and Building Materials, 125, pp. 1066-1079.

Zhang, M.-H. and Malhotra, V. M. (1996) 'High performance concrete incorporating rice husk ash as a supplementary cementing materials', ACI Materials Journal, 93(6), pp. 629-636. 